\title{
Assessment of Nursing Services and Clients' Satisfaction in Oncology Hospital
}

Mukti Rita Gomes*

Vice Principal, Universal Nursing College, Mohakhali, Dhaka, Bangladesh

DOI: $10.36347 /$ sjmcr.2021.v09i02.012

| Received: 08.02.2021 | Accepted: 19.02.2021 | Published: 22.02.2021

*Corresponding author: Mukti Rita Gomes

Abstract

Research on nursing service and satisfaction with care during hospitalization in oncology patients has been limited. Bangladesh has seemingly got an alarm bell for the higher rate of cancer-related death, which is badly affecting the main workforce of the country. Some recent studies on this disease described a poor state of cancer treatment, care and others facilities in this country where around 2.5 lac people are being affected every year for many reasons. The healthcare team's goal is to provide the patient with the best health care and service possible. The service providers are in constant effort to better meet the patients' needs and expectations. The major objective of the study was to assess the association between patients' satisfaction with nurses' care facilities and symptom severity and other objective of the study are to evaluate test-retest of a satisfaction survey in this study population. (1) To identify the problems in nursing staffing in the Oncology Hospital. (2) To assess the level of patients' satisfaction in Oncology Hospital. The study is a descriptive cross-sectional type with qualitative approach. Data were collected by using questionnaires from registered nurses \& patients. The study area is National Institute of Cancer Research and Hospital in Dhaka City. Result indicated that among the respondent $32 \%$ answered that they did not get sufficient time to treat \& care their patient and $68 \%$ replied that they get sufficient time to treat \& care their patient. The study reveals that registered nurses have received any training in the relevant field. $70.6 \%$ nurse replied that they are not received proper training and only $29.4 \%$ nurse said that they have received training from the hospital. The study presents that satisfaction with the assistance received from nurses. 18\% respondent replied that they are very satisfied, $14 \%$ satisfied, $44 \%$ moderately satisfied \& others $24 \%$ dissatisfied with assistance received from nurse. Questions were asked what the patients think on well communication, $25 \%$ replied that they are dissatisfied and $75 \%$ replied that they are satisfied with the well communication of the nurses with their patient. Recommendation of the study, (1) Help hospital manager and policy makers through proper planning to develop trained registered nurse of Oncology Hospital and (2) Improve nursing service by changing the attitudes towards of clients and increase patients' satisfaction with the nurses to pay attention.

Keywords: cancer treatment, nursing service, Oncology Hospital.

Copyright $($ C) 2021 The Author(s): This is an open-access article distributed under the terms of the Creative Commons Attribution 4.0 International License (CC BY-NC 4.0) which permits unrestricted use, distribution, and reproduction in any medium for non-commercial use provided the original author and source are credited.

\section{INTRODUCTION}

Cancer is an abnormal growth of cells caused by multiple changes in gene expression leading to deregulated balance of cell proliferation and cell death and ultimately evolving into a population of cells that can invade tissues and metastasize to distant sites, causing significant morbidity and, if untreated, death of the host. There are over 100 different types of cancer, and each is classified by the type of cell that is initially affected. Cancers are caused by exogenous chemical, physical, or biological carcinogens.

Although cancer can occur at any age, it is usually considered a disease of aging. The average age at the time of diagnosis for cancer of all sites is 67 years, and about $76 \%$ of all cancers are diagnosed at age 55 or older. Although cancer is relatively rare in children, it is the second leading cause of death in children ages 1-14. In this age group leukemia is the most common cause of death. Thus, even though the overall death rates due to cancer have almost tripled since 1930 for men and gone up over $50 \%$ for women, the age-adjusted cancer death rates in men have only increased 54\% in men and not at all for women. World Health Organization (WHO) estimates that some 84 million people will die of cancer between 2005 and 2015 around the world. In 2007, there were 7.9 million deaths from cancer, around 13 percent of all deaths. 
Like many other countries in the world cancer in Bangladesh is one of the major killer diseases. The National Institute of Cancer Research and Hospital (NICRH), Dhaka, started a cancer registry in 2005 for the first time in Bangladesh with technical assistance from the World Health Organization (WHO). Data were collected from 24,847 cancer patients who attended the NICRH for the first time. Essential information (confirmed diagnosis) could be made available for 18,829 cases, and they are included in this analysis. among them $10,847(57.6 \%)$ were males. lung cancer was the leading cancer $(17.3 \%)$, followed by cancers of breast $(12.3 \%)$, lymph nodes and lymphatics $(8.4 \%)$ and cervix $(8.4 \%)$ for sexes combined in all ages. in males' lung $(25.5 \%)$ and in females' breast $(25.6 \%)$ and cervical $(21.5 \%)$ cancers were predominant. in children aged 14 years or younger lymphoma, retinoblastoma, osteosarcoma, leukaemia and kidney cancers were most prevalent. lung cancer in males, and cervical and breast cancer in females constitute $38 \%$ of all cancers in Bangladesh (cancer registry report 2005-2007). according to the latest who data published in april 2011 oral cancer deaths in Bangladesh reached 11,562 or $1.21 \%$ of total deaths. the age adjusted death rate is 12.52 per 100,000 of population ranks Bangladesh $4^{\text {th }}$ in the world. At present, there are one million (10 lakh) cancer patients in Bangladesh while approximately 200,000 new patients, mostly women, are added every year creating a social burden on the country. The country's women are now in danger of being affected by cervical cancer, one of the sexually transmitted diseases that claim the life of 18 women every day in the country for lack of awareness. [5]

According to the draft annual report 2005 of the national institute of cancer research and hospital, top five cancers in male are - lungs 24.7 per cent, unknown primary site 8.1 per cent, larynx 7.3 per cent, lymphatic and lymph node 7.3 per cent and esophagus 5.1 per cent. to five cancers in females are cervix 24.6 per cent, breast $24 \check{1}$ per cent, lungs 5.5 per cent, oral cavity 4.1 per cent and ovary 3.8 per cent.

\section{Background of the Study; Oncology Nursing}

Nursing as a profession is dedicated to the care of patients and families throughout health and illness and across all settings of care. Oncology nurses assess and plan care to address the multidimensional spectrum of needs for those efforts focused on cancer prevention, and they also are pivotal in the emerging area of clinical genetics for prevention and early detection of cancer. From diagnosis through end of life, nurses play an intricate role in enhancing the quality of life (QOL) of their patients. Nurses are in a unique position to influence both the physiologic and psychological wellbeing of their patients, helping cancer survivors to cope with the immensity of their experience and its resulting impact on their lives (McCorkle, Grant, FrankStromborg, \& Baird, 1996; Miaskowski \& Buchsel, 1999).
Oncology nurses, individually and collectively, have led many initiatives that have resulted in attention to concerns such as pain, fatigue, sexuality, fertility, family coping, longterm sequela of treatment, and numerous other areas pertaining to survivorship (Brant, 1996; Ferrell, 1996; Grant, Padilla, \& Greimel, 1996). Oncology nurses also have led important initiatives addressing psychosocial needs and have advocated for improved end-of-life care. Many of these educational efforts have been led by the Oncology Nursing Society (ONS), a national professional organization whose efforts have been especially important in raising awareness of survivorship concerns and providing extensive education to practicing nurses (Wilmoth \& Sanders, 2001).

Oncology nurses have addressed many of the physical burdens associated with cancer survivorship. Fatigue, nutrition, sleep disturbances, menopausal symptoms, and short- and long-term sequela of treatment have been a key focus in oncology nursing. Efforts to better assess these symptoms and provide patient education have greatly enhanced comfort and QOL for survivors (Ferrell, Grant, Dean, Funk, \& Ly, 1996; Ferrell, Grant, Funk, et al., 1996; Ganz, 2001). [6]

Psychological concerns such as fear, anxiety, depression, and living with uncertainty have been addressed through model oncology nursing education, intervention, and research programs. Nurses assess psychological symptoms, offer supportive care and education, and are involved in coordination of interdisciplinary services by colleagues in social work, chaplaincy, rehabilitation, and psychology (Brant, 1996; Carroll-Johnson, Gorman, \& Bush, 1998; Dow, Ferrell, \& Anello, 1997; Ferrell, Grant, Funk, Otis-Green, \& Garcia, 1997a; Quigley, 1989).

Social concerns emphasized in oncology nursing have included attention to sexuality, fertility, appearance, and counseling of partners and children. Recognition of the economic burden of cancer, employment concerns, and adjustment to life beyond cancer treatment have been important areas of contribution (Hoffman, 1991). Nurses have developed, implemented, and evaluated programs to support families through the cancer survivorship journey (Dow \& Ferrell, 1998; Ferrans, 1994; Ferrell et al., 1997c; Ferrell \& Hassey-Dow, 1998).

\section{Key Oncology Nursing Standard}

Four key ONS documents deemed as representative of the standard of oncology nursing care were evaluated for content pertaining to nursing care and cancer survivorship. Two monographs outlining oncology nursing standards, Standards of Oncology Nursing Education, Generalist and Advanced Practice Levels (ONS, 1995) and Statement on the Scope and 
Standards of Oncology Nursing Practice (Brant, 1996), as well as two psychosocial texts, Psychosocial Dimensions of Oncology Nursing Care (Burke, 1998) and Psychosocial Nursing Care Along the Cancer Continuum (Carroll-Johnson et al., 1998), were included in the review. Ten critical content areas consistent with the outline of the overall NCPB/IOM report were considered: description of population of cancer survivors, primary care, short- and long-term complications, prevention of secondary cancers, detecting recurrent and secondary cancers, treatment of recurrent cancer, quality of life issues, rehabilitative services, palliative and end-of-life care, and quality of care.

Psychosocial Nursing Care Along the Cancer Continuum (Carroll-Johnson et al., 1998) focused on psychosocial experiences that accompany a cancer diagnosis and the emotional and psychological responses to these experiences. A focus on nursing interventions provides a means to address and improve care for patients facing the psychosocial challenges that accompany survivorship. Many sections of the book also contain small sections on survivorship, which address specific issues that survivors face in regards to coping, support, fatigue, chronic illness, QOL, and oncology nursing care. [7]

One means of evaluating the knowledge of nurses within a specific area is to evaluate the textbooks used within formal education programs. To provide similar information for this article, a review of five key oncology texts was conducted to assess the amount and level of survivorship content that was included. The texts reviewed included Cancer Nursing (2nd edition) (McCorkle et al., 1996), Cancer Nursing, Principles, and Practice (Yarbro, Frogge, Goodman, \& Groenwald, 2000), Oncology Nursing (4th edition) (Otto, 2001), Oncology Nursing: Assessment and Clinical Care (Miaskowski \& Buchsel, 1999), and Handbook of Oncology Nursing (3rd edition) (Johnson \& Gross, 1998).

Four of the books had content describing populations of cancer survivors. The most prevalent survivorship content areas present in all the books were primary care and quality of care. Content applying to short- and long-term complications, descriptions of populations of cancer survivors, QOL, palliative and end-of-life care, and detection of recurrent and secondary cancers also received adequate attention across the textbooks. Prevention of secondary cancers, treatment of recurrent cancer, and rehabilitative services received little attention in all the textbooks and were absent in several texts.
Only two textbooks had chapters with "survivor" in the title. "Survivorship and QOL Issues" (Grant et al., 1996) and "Surviving Breast Cancer" (McCorkle, 1996) included content such as the definition of survivor, survivorship stages and phases, psychological and psychosocial aspects, QOL, economic issues confronting patients and family, and spiritual and ethical concerns. A section in Cancer Nursing, Principles and Practice (Yarbro et al., 2000) included three chapters specific to survivorship issues: "Psychosocial Responses to Cancer," "Physical, Economic, and Social Issues Confronting Patients and Families," and "Spiritual and Ethical End-of-Life Concerns." [8]

\section{Role and Duties of Oncology Nurses}

Oncology nursing involves working with cancer patients who are either chronically or critically ill, primarily in hospitals. Oncology nurses provide and supervise care for their patients by monitoring their patients' physical conditions, prescribing medications, and formulating system management strategies. They may work with children or adolescents with cancer or blood disorders, or adults or seniors.

Oncology nurses' practice in a variety of settings including acute care hospitals, ambulatory care clinics, private oncologists' offices, radiation therapy facilities, home healthcare agencies, and community agencies. They practice in association with a number of oncologic disciplines, including surgical oncology, radiation oncology, gynecologic oncology, pediatric oncology, and medical oncology.The majority of ONS members are involved in direct patient care and practice at the generalist level, with $43 \%$ working in a hospital/multihospital system, $24 \%$ in the outpatient/ambulatory care setting, $11 \%$ in physician offices, and $3 \%$ in hospice or home care. Positions in the outpatient and home care setting have increased as more patients are being treated out of the hospital setting. The roles of the oncology nurses vary from the intensive care focus of bone marrow transplantation to the community focus of cancer screening, detection, and prevention.

The following discussion on the role of the oncology nurse focuses on patient assessment, patient education, and coordination of care, direct patient care, symptom management, and supportive care. To illustrate how varied the role may be and its importance across the continuum of cancer care, examples related to the role of the oncology nurse in direct patient care, symptom management, and supportive care are provided. [9] 
a) Inpatient Care; The primary role of an oncology nurse before the 1970s dealt mostly with inpatient care. This role, while still of great importance, is now only a small part of their overall responsibilities. Still nurses must provide everyday needs and assist in treatments for those who are required to stay in the hospital. Being a direct caregiver, an oncology nurse is often the face of the hospital to the patient, providing the essentials in the way of diet and medicine, as well as answering questions and giving comfort.

b) Patient Assessment; Nurses are expected to be expert in assessing a patient's physical and emotional status, past health history, health practices, and both the patient's and the family's knowledge of the disease and its treatment. The oncology nurse reviews the treatment plan with the oncologist, is aware of expected outcomes and possible complications, and independently assesses the patients' general physical and emotional status. It is essential that a detailed nursing history and physical examination be completed. An oncology nurse is expected to be aware of the results and general implications of all relevant laboratory, pathology, and imaging studies. Assessment of the patient's understanding of the disease and proposed treatment is fundamental in allaying anxiety and formulating a care plan. Obtaining this information will help avoid misunderstanding and confused expectations. Thorough patient preparation improves compliance with treatment programs and may impact treatment outcomes as well. A nursing care plan is developed in response to the particular needs identified from the assessment. At a minimum, this plan promotes (1) the patients; understanding of therapy goals, treatment schedules, and possible side effects of therapy; (2) physical and psychological preparation for therapy; (3) physical and psychological comfort; and (4) compliance. c) Patient Education; The nurse often has a better opportunity than any other member of the healthcare team to develop the required rapport for effective educational efforts with patients and their families. Patient and family education starts before therapy and continues during and after therapy. Continual reinforcement throughout the treatment course helps to ensure success. The ONS has enhanced this definition by recommending the following patient education outcome criteria: The patient and/or family should be able to (1) describe the state of the disease and therapy at a level consistent with the patient's educational and emotional status; (2) participate in the decision-making process pertaining to the plan of care and life activities; (3) identify appropriate community resources that provide information and services; (4) describe appropriate actions for highly predictable problems, oncologic emergencies, and major side effects of the disease and/or therapy; and (5) describe the schedule when ongoing therapy is predicted.

d) Coordination of Care; The oncology nurse plays a vital role in coordinating the multiple and complex technologies now commonly employed in cancer diagnosis and treatment. This coordination encompasses direct patient care; documentation in the medical record; participation in therapy; symptom management; organization of referrals to other healthcare providers; both patient and family education; as well as counseling throughout diagnosis, therapy, and follows up. The nurse should serve as the patient's first line of communication. Ideally, the patient and family should feel free to contact the oncology nurse by phone during the entire treatment program. Many patients travel long distances, so the importance of communication by telephone must be emphasized. It allows continuous patient communication, early recognition of emergencies, and regular emotional support. 
e) Direct Patient Care; The majority of ONS members provide direct patient care involving chemotherapy. National certification for chemotherapy currently does not exist. An important responsibility of nurses involved in the delivery of chemotherapy is to ensure that the correct dose and drug are administered by the correct route to the right patient. Complex regimens of potentially lethal drugs are being employed in a variety of settings. A survey of ONS members to determine extent and type of medication errors noted that $63 \%$ of the respondents reported evidence of medication errors occurring in their patient care settings. These errors included errors in dosing, incorrect drugs administered to patients or drugs administered by an incorrect route, and errors in administration and preparation. A report from the Institute of Medicine noted that more people die annually from medication errors than from workplace injuries. A national agenda with state and local implications for reducing medical errors and improving patient safety has been set forth. Recommendations are devoted to a safer healthcare system. In 2001, the ONS published its position statement on "Prevention and Reporting of Medication Errors," [10] which provides recommendations for practice, policy, systems, education, and research for the delivery of safe care. Individual institutional guidelines should be developed to minimize the risk of chemotherapy errors. These guidelines should include a reporting system for errors and a systematic way to review current practice to provide changes to prevent repetition of errors.

\section{Responsibilities}

The responsibilities of oncology nurses extend beyond direct patient care to include consultant, patient educator, researcher, and management. They collaborate closely with physicians and other members of the healthcare team to ensure the highest quality of care to patients.

\section{The Duties And Responsibilities Of Oncology \\ Nursing Professionals Include The Following:}

1. Develop individualized care plans for patients under their care.

2. Collaborate with a multidisciplinary health care team to share knowledge and expertise.

3. Identify and treat cancer-related health issues.

4. Perform cancer research to improve treatment protocols provided to cancer patients.

5. Provide supportive resources for patients and their families to foster positive outlook and morale.
6. Educate patients and their families with regard to treatment expectations.

7. Monitor and record the progress of patients on an ongoing basis.

8. Document patient's response to medication and all treatment.

Oncology nurses provide a broad range of services from direct care and cancer prevention through rehabilitative, palliative, and supportive services. Some oncology nurses specialize in working with children and are referred to as pediatric oncology nurses.

\section{Qualifications}

The oncology nurse must possess knowledge in each of the following areas:

1. Anatomy and physiology

2. Oncology nursing practice

3. Pharmacology

4. Nutrition

5. Psychosocial aspects of cancer for patients and their families.

6. Principles of radiation chemotherapy and possible complications of treatment.

7. Education and Training Requirements

Clinical work plays a major part of most bachelors' programs and occurs in a variety of healthcare settings. Students will further develop their skills by participating in nursing laboratories Nearly 50 percent of the nursing program will be devoted to clinical and laboratory practice in such settings as large general hospitals, smaller community0based hospitals, cancer-based clinics, and rehabilitation centers. [11]

Bachelor's programs offer practical experience combined with theoretical study and the development of comprehensive clinical and patient-relationship skills to enable graduates to work as competent nursing professionals. Study will foster independent and critical thinking skills and enhance student's awareness of preventative health measures.

\section{Objectives of the Study}

1. To know the system and nature of nursing services.

2. To identify the problems in nursing staffing in the Oncology Hospital.

3. To know the level of clients' satisfaction in Oncology Hospital.

4. To find out the relationship between staffing of nursing services and patient care.

\section{Operational Definition \\ Cancer:}

- Cancer is a disease characterized by the uncontrolled growth of abnormal cells.

- Any of a group of diseases caused by unrestricted multiplication of cells in any 
organ or tissue that can spread throughout the body.

\section{Cancer Screening:}

- A program to detect cancer in its asymptomatic stage. (Park 2000, and American Cancer Society 2006).

\section{Breast cancer:}

- A malignant neoplasm of breast tissue in women between the age of 30 and 50 may present as a small painless lump, thick or dimpled skin or nipple retraction, nipple discharge, ulceration and enlarged axillaries lymph nodes, metastases through the lymphatics to axillaries lymph nodes and to bone, lung, liver and brain.

Gynaecology:

- The study of diseases of the female reproductive organs and the breasts.

\section{Contraceptives:}

- Preventive methods to help woman avoid unwanted pregnancies resulting from coitus.

Tubectomy:

- Excision of a portion of the uterine tubes (American Cancer Society 2006).

\section{Malignant Tumor}

Uncontrolled division of the body's cells results in the formation of malignant tumor. Cancer indicates development of malignant tumor in the body which if not removed promptly can metastasize to other places in the body and can invade several organs, eventually leading to death.

\section{Stages of Cancer}

The stage is described as 'unknown'. Sometimes 3 stages of cancer development are described. Staging system is designed, taking into consideration the original site of the Primary Tumor, Size Of The Tumor, Number Of Tumors, spreading of cancer into lymph nodes, nearby organs and distant organs, cell type and tumor grade to discuss 4 stages of cancer development.

Carcinoma in Situ; If this initial phase is not taken into consideration, then cancer development is described in 3 stages.

Stage "0"; This stage is also known as 'stage 0 '. Abnormal cells (the cells which may turn into cancerous cells) are detected in the body but they are present only in the layer of cells in which they had developed.

Stage I; This describes 'localized' cancer. Tumor is very small. Growth of cancer restricted to the organ in which it began is termed as stage I cancer. The cancer has not spread beyond the primary site. It is possible to remove the cancer surgically.

Stage II; Cancer spreads to the nearby lymph nodes, tissues or organs, it is described as 'stage II cancer'. It is still possible to curb the growth of cancer with proper treatment.

Stage III; Cancer usually spreads to nearby lymph nodes, organs or even to distant lymph nodes and organs. It is difficult to decide where stage III ends and stage IV starts.

\section{Oncology Patients Care Delivery by Nursing Personnel}

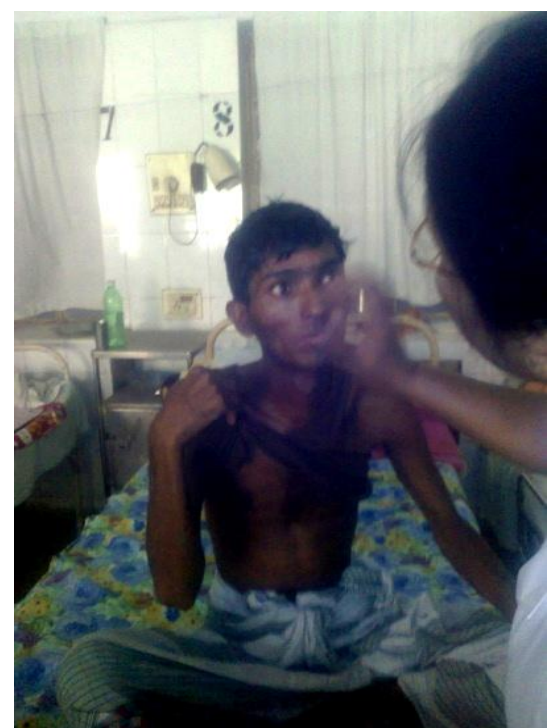

Literature Review (Oncology Nursing as a Specialty)

Historically, nurses have had a special role in the care of patients with cancer, a role that was especially significant in those few institutions devoted exclusively to cancer care before the National Cancer

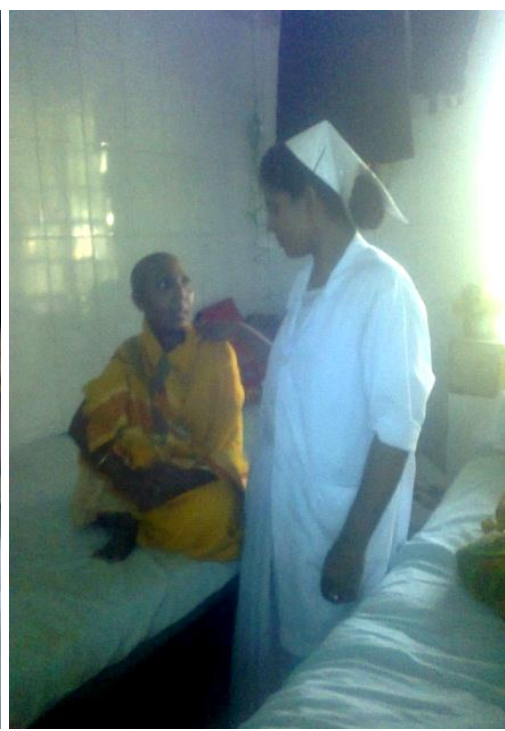

Act of 1971. However, the expanded research and treatment program against cancer that has occurred during the past quarter century has been a catalyst for the development of oncology nursing as a separate specialty. The recognition of cancer as a major national 
health problem was key to formally establishing the specialty of oncology nursing. This increased attention to cancer coincided with and complemented a major new emphasis in the nursing profession toward expanded roles in comprehensive patient care. Many oncology nurses first worked both as nurses and data managers for cancer research studies. As oncology called for increasingly more complex therapy, the collaborative relationship between nurse and physician became the best way to provide uniquely comprehensive patient care. [12]

\section{Oncology Nursing Education}

Educational curricula have been developed and implemented to provide oncology nurses with an appropriate understanding of cancer biology, epidemiology, prevention, treatment, nursing practice issues, and trends in cancer care. Several cancer nursing texts and journals, such as the Oncology Nursing Forum, Cancer Nursing, and Seminars in Oncology Nursing, deal with these topics in appropriate formats.

Membership in the ONS offers opportunities for the study and education necessary to qualify for the OCN and AOCN credentials by passing the certification examinations. Increasingly, master's level preparation is specified in many oncology job descriptions. For example, a master's degree is required for oncology clinical nurse specialists and nurse practitioners. Currently, 26\% of the ONS members are pursuing graduate education, and $10 \%$ are doctoral students. [13]

\section{Oncology Nursing Research}

The development of oncology nursing research to guide oncology nursing practice has been extraordinary over the past 25 years. From a modest beginning in the 1970 s, nursing research evolved in the 1980 s to the identification of research priorities, companion studies in cooperative group clinical trials, as well as initial programs of research and funding. In the 1990s, continued advances have included mature programs of research, multi-site studies, increased funding sources, research utilization through state-ofthe-knowledge conferences, and major areas of studies (e.g., fatigue, quality of life, pain) that are having a major impact on cancer care. The ONS has conducted five research priority surveys since 1981 . The top 10 research priorities from the most recent survey included pain, prevention, quality of life, risk reduction/screening, ethical issues, neutropenia/immunosuppression, patient education, stress, coping and adaptation, detection, and cost containment. As a result of today's health-care environment, nurses are being challenged by insurers, health policy makers, and managed-care organizations to demonstrate the effectiveness of their care through research that examines the link between specific nursing interventions and patient outcomes.
Nursing Care Related To Specific Cancer Therapies

Nursing care of patients receiving surgery, radiotherapy, chemotherapy, or biologic therapy, alone and in combination, begins with physical and psychological preparation. The oncology nurse reviews the treatment plan with the oncologist, is aware of expected outcomes and possible complications, and independently assesses the patient's general physical and emotional status.

A nursing care plan is developed in response to the particular needs identified from the assessment. At a minimum, this plan will promote (1) the patient's understanding of therapy goals, treatment schedules, and possible side effects of therapy; (2) physical and psychological preparation for therapy; (3) physical and psychological comfort; and (4) compliance. Patient and family education starts before therapy and continues during and after therapy. Reinforcement helps ensure success. Appropriate written and visual teaching aids may be utilized as well as referrals to other professionals or community programs, such as cancer support groups.

\section{Surgery}

Surgery is the most frequently used treatment for cancer. A definitive diagnosis of cancer requires tissue confirmation and most patients undergo some type of surgical procedure early in the course of their treatment. Beyond diagnosis, surgery is the definitive means of cure for most solid tumors and has many other applications in cancer management. Surgical procedures are performed for cancer prevention, primary tumor removal, disease staging, tumor debulking, hormonal ablations, disease palliation, reconstruction, and placement of vascular devices.

The trend to shift surgical procedures from inpatient to outpatient facilities continues. Nurses are challenged to ensure quality patient outcomes, while controlling costs. Clinical pathways have been developed to standardize approaches to care. They provide patients with a treatment course that results in the best possible outcome, while using fewer resources and less time. [14]

\section{Radiation Therapy}

Radiation therapy may be used to cure, control, or palliate cancer. It may be the primary treatment for cancers such as Hodgkin's disease or seminoma. It may be effective in achieving control from months to years for recurrent breast cancer or lung cancer. Radiation therapy can be very effective in palliating symptoms such as pain or obstruction. It may be combined with chemotherapy, surgery, or immunotherapy. Examples include preoperative combination radiotherapy plus chemotherapy for rectal cancer or radiation following breast surgery for early breast cancer or for locally advanced breast cancer. 
Nursing care of the patient receiving radiation therapy focuses on preparing the patient physically and psychologically for therapy. Pretreatment assessment includes knowledge of the treatment plan and goal of therapy, physical assessment with particular attention to areas that may be affected by radiation, nutritional assessment, the patient's and family's understanding of the disease process and proposed treatment plan, the patient's knowledge of possible side effects, and practical problems, such as patient's transportation to the treatment center.

\section{Chemotherapy}

Providing nursing care to patients receiving chemotherapy presents many challenges. The majority of patients receiving chemotherapy are treated in ambulatory-care settings, and some patients may even receive treatments in their homes. Oncology nurses are faced with increased responsibility for coordinating quality care with fewer resources.

The delivery of chemotherapy is primarily the responsibility of oncology nurses. The nurse must have knowledge of the pharmacology of antineoplastic agents, proper techniques of drug preparation and administration, drug interactions, and possible adverse effects of individual agents. The nurse must be skilled in the technique of venipuncture and the management of various types of venous access devices and drug administration systems. In addition, nurses prepare patients and families to manage anticipated side effects of chemotherapy and to report symptoms of potentially serious side effects early to avoid serious consequences. The ONS recognizes that chemotherapy administration is complex and requires training and clinical preparation beyond the basic nursing education. Nursing practice varies from state to state, but the ONS recommends that only registered nurses who have received this additional education and training administer chemotherapy. National certification for chemotherapy currently does not exist. Each institution should have written policies for chemotherapy certification, administration of antineoplastic drugs (all routes), safe drug handling and disposal, management of untoward reactions, such as allergic reactions, and methods for documentation. [15]

\section{Biotherapy}

Biotherapy is often considered the fourth modality of cancer therapy. Biologic therapy may alter host immune response to the tumor or be primarily aimed at reconstituting normal host functions, such as granulocyte repopulation. On occasion, the precise function of a noncytotoxic pharmacologic agent may be unknown, as in the case of levamisole. Biologic agents include the interferons, interleukins, vaccines, colonystimulating factors, and monoclonal antibodies. These often are used in conjunction with other cancer therapies, such as chemotherapy, radiation therapy, or surgery.
The two most common side effects associated with biotherapy are a flu-like syndrome and fatigue. Intradermal, subcutaneous, and intralesional vaccines can cause localized skin inflammation and systemic side effects, such as fever, chills, diaphoresis, and fatigue. High-dose cytokines can result in toxicities affecting nearly all organ systems. The hematopoietic growth factors are generally well tolerated aside from bone pain. Since many of these agents are administered subcutaneously, oncology nurses must teach patients or family members how to prepare and inject the drugs as well as to manage possible side effects. [16]

\section{Supportive Care}

Oncology nurses are closely involved with numerous supportive care issues encountered by cancer patients and their family. This chapter does not allow a detailed discussion of the numerous areas of supportive and palliative care, but two areas deserve special mention, that is, the involvement of nurses in pain management and in survivorship.

Nursing care should be planned to promote patient comfort, provide patients and their families with information related to pain control, provide information about and assistance with behavioral and physical interventions, prevent and alleviate side effects of pharmacologic therapies, and promote patient compliance with therapy and required follow-up. The nurse should explain the rationale of interventions and provide time for patient and family questions. Patient education should include the names of the pharmacologic agents, dosage schedules, side effects, interventions to alleviate nausea and vomiting, such as antiemetics, and interventions to alleviate constipation. The nurse should monitor the effectiveness and side effects of pharmacologic interventions, respiratory status, bowel functioning, as well as mental and cognitive functioning. The patient and family must know how to contact medical personnel in case of an emergency and should feel free to do so. [17]

\section{Survivorship}

Over $50 \%$ of individuals who are diagnosed with invasive cancer will live beyond 5 years, and most will be considered cured. Thus, issues of survivorship and living with the effects of cancer and its treatment are a significant concern. This is evidenced by the emphasis on rehabilitation. The ONS was the first professional group to provide a practical definition of cancer rehabilitation as a "process by which individuals within their environments are assisted to achieve optimal functioning within the limits imposed by cancer."

The National Coalition of Cancer Survivors and the American Cancer Society have brought survivorship issues to the public and are promoting rehabilitation as the first phase in preparing cancer survivors to lead fulfilling lives. Bushkin, a cancer 
nurse who died of cancer in 1993, said "surviving a chronic illness is a hard fight." She also provided insight and understanding into the process of being a cancer survivor through her teaching, caring, and conceptualization of the process of survival, best expressed in her lecture entitled "Signposts of Survivorship" [18]. She provided, by word and example, a mechanism to combine the challenges of life into a cohesive plan for living. [19]

\section{Methodology Study Design}

This is a descriptive cross sectional type of study carried out among the National Institute of cancer Research and Hospital in Dhaka city. Age group, gender, salary range etc were also included in the study.

\section{Place of the Study}

The study was conducted in National Institution of Cancer Research and Hospital at Mohakhali, Dhaka-1212. This hospital consists of total 150 beds, 11 units, 4 wards of which 2 male wards and 2 female wards. Total number of doctors is 249 and total number of nurses is 65 . Other facilities in the hospital are noted below;

Others Machineries; Radiology, Linear Accelerator; Linac Accelerator (Megavolt); Cobalt- 60 Unit; Cobalt100

Outdoor; Chemotherapy- Yes, Day Care- Yes, Counseling/health education room- Yes

\section{Period of Study}

The total study period includes was 18 months and title selection and approval from the board, questionnaire preparation, pre-testing of questionnaire and finalization of questionnaire, data collection and data analysis and report writing. The total study period was;

\section{Study Population}

Two groups of respondents were selected for this study.Registered Nurses of the hospital and the patients who are getting services from the hospital.

\section{Data Collection Procedure}

Data were collected by using following method;

a. A pre-tested structured questionnaire was used to get information from the nurses (Annex 1)

b. A pre-tested structured questionnaire was use to get information from the patients (Annex 2)

Translations of questions into Bangla, the local language were agreed upon to ensure consistency. The nurse's response questionnaire had 4 sections. Section 1 contains their training qualification. Section 2 contains how sincerely they're related to their job. Section 3 their demographic information like age, gender, salary range. Section 4 focuses on their job satisfaction. Patient's response questionnaire was designed to collect information how do they rank the service they got from the nurses.

\section{RESUlT AND DisCUSSION}

Nurse's Feedback

Table. Age of the Nurses

\begin{tabular}{|l|l|l|}
\hline Age range & No. of Respondent & Percent (\%) \\
\hline $31-35$ & 9 & 17.6 \\
\hline $36-40$ & 13 & 25.5 \\
\hline $41-45$ & 9 & 17.6 \\
\hline $46-50$ & 12 & 23.5 \\
\hline 51 to highest & 6 & 11.8 \\
\hline Total & $\mathbf{6 0}$ & $\mathbf{1 0 0 . 0}$ \\
\hline
\end{tabular}

It was found that the maximum number of the respondents was from the age group 36-40 years and in percentage this was almost $26.66 \%$ and along with this low percentage of respondents was found from the age group 51 to highest years. 

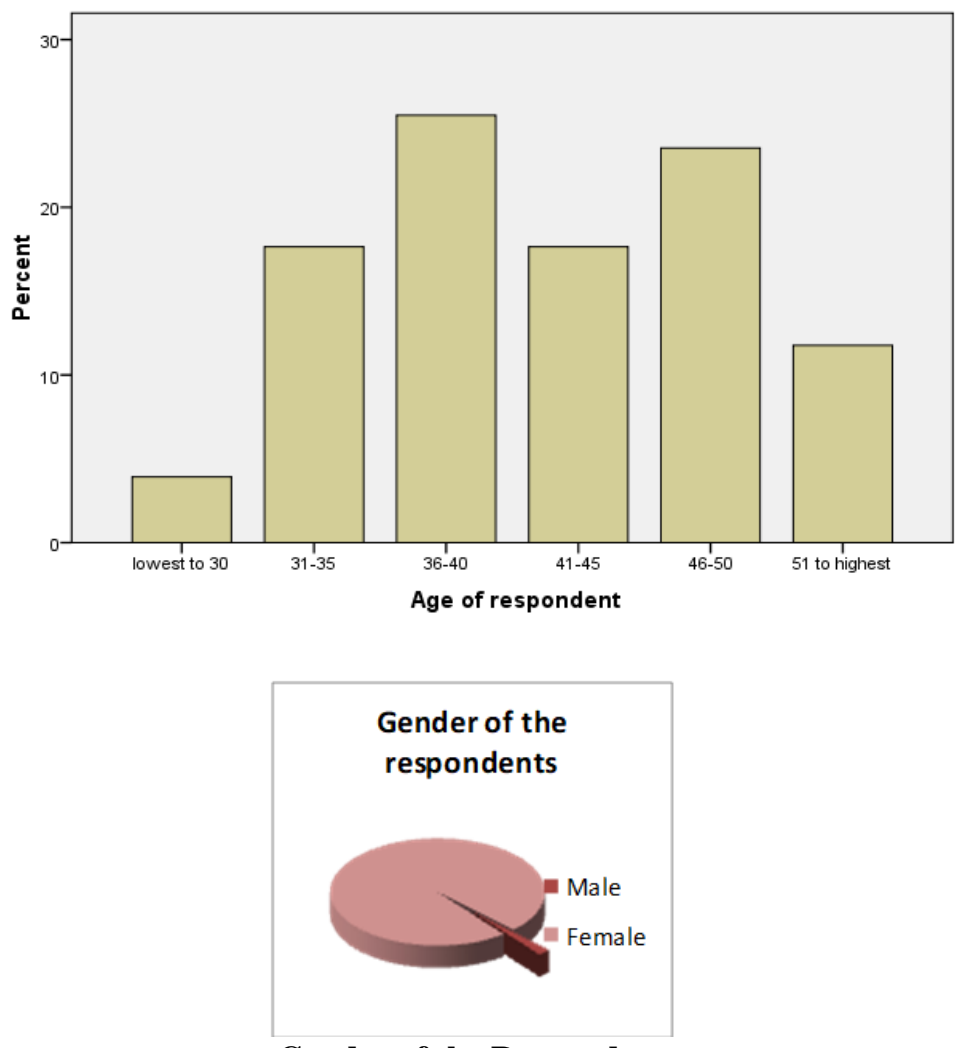

Gender of the Respondent

The gender of the respondent predominantly was female and in percentage it occupies $98 \%$ of the total respondent whereas only $2 \%$ was male.

Income Analysis; Salary Range

\begin{tabular}{|c|c|c|c|}
\hline Salary Range (BDT) & Frequency & Percentage & Statistical information \\
\hline $10000-15000$ & 2 & 3.9 & \multirow{5}{*}{$\begin{array}{l}\text { Mean } 21960 \text { BDT } \\
\text { Std. deviation } 5227.66\end{array}$} \\
\hline $15000-20000$ & 24 & 47.1 & \\
\hline $20000-25000$ & 3 & 5.9 & \\
\hline $25000-30000$ & 21 & 41.2 & \\
\hline More than 30000 & 1 & 2 & \\
\hline
\end{tabular}

The maximum numbers of respondents receive salary in the range of 15,000 BDT to 20,000 BDT. Only $2 \%$ percent of the nurses get salary more than 30,000
Tk. per month. The respondent nurses have average income BDT 21960 with standard deviation 5227.66.

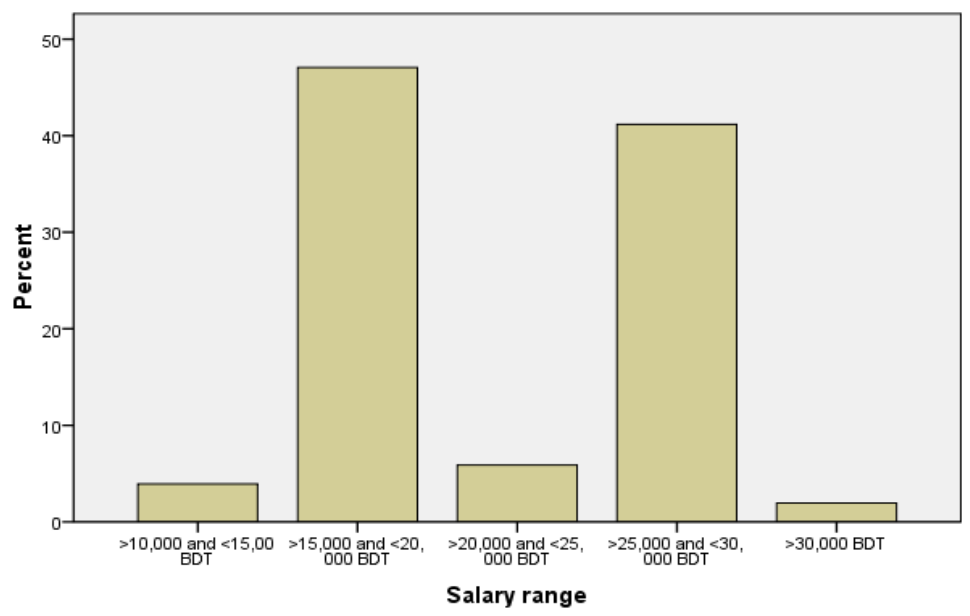




\section{Cross Tabulation Analysis: Salary Range with Working Range}

From the above cross tabulation analysis, it is noticeable that the almost $47.9 \%$ respondent income range is within $15,000 \mathrm{BDT}$ to $20,000 \mathrm{BDT}$ and all of them have experience more than 4 years in the respective organization. Second significant income range is $25000 \mathrm{BDT}$ to $30000 \mathrm{BDT}$ that occupies $41.2 \%$ of the total respondent and significantly $39.6 \%$ of them have experience more than 4 years.

\begin{tabular}{|l|l|l|l|l|l|}
\hline \multicolumn{7}{|l|}{ Duration of work } \\
\hline Salary Range & 6 months-1 year & 2 Years-4 Years & More than 4 yrs. & More than 5 yrs. & Total \\
\hline $10000-15000$ & $0 \%$ & $0 \%$ & $0 \%$ & $4.2 \%$ & $4.2 \%$ \\
\hline $15000-20000$ & $0 \%$ & $2.1 \%$ & $31.2 \%$ & $14.6 \%$ & $47.9 \%$ \\
\hline $20000-25000$ & $0 \%$ & $0 \%$ & $6.2 \%$ & 0 & $6.2 \%$ \\
\hline $25000-30000$ & $2.1 \%$ & $0 \%$ & $29.2 \%$ & $8.3 \%$ & $39.6 \%$ \\
\hline$>30000$ & $0 \%$ & $0 \%$ & $0 \%$ & $2.1 \%$ & $2.1 \%$ \\
\hline Total & $\mathbf{2 . 1 \%}$ & $\mathbf{2 . 1 \%}$ & $\mathbf{7 0 . 8 \%}$ & $\mathbf{2 5 \%}$ & $\mathbf{1 0 0 \%}$ \\
\hline
\end{tabular}

Here a Pearson Co-relation test has been done to test the underlying correlation factor in between the income range of the respondent and with experience in that institution. From the analysis it is found that the correlation factor for these two variables is -0.138 with significance .198 (two tails) that represents inverse relationship among the variables. So, from this correlation factor it is apparent that although the nurses gain experiences their monthly income level do not change significantly.

\begin{tabular}{|l|l|l|l|}
\hline \multicolumn{2}{|l|}{ Pearson Correlation Analysis } & Monthly Income & Experience \\
\hline Monthly Income & Pearson Correlation & 1 & -0.138 \\
\cline { 2 - 4 } & Sig. (2-tailed) & & 0.198 \\
\hline
\end{tabular}

Availability of the Training

\begin{tabular}{|l|l|l|}
\hline Reply & No. of Respondent & Percent (\%) \\
\hline Yes & 42 & 30 \\
\hline No & 18 & 70 \\
\hline Total & 60 & 100.0 \\
\hline
\end{tabular}

The table reveals that registered nurses have received any training in the relevant field. $70 \%$ nurses have not received any training and only $29 \%$ said that they have received training on Oncology nursing.

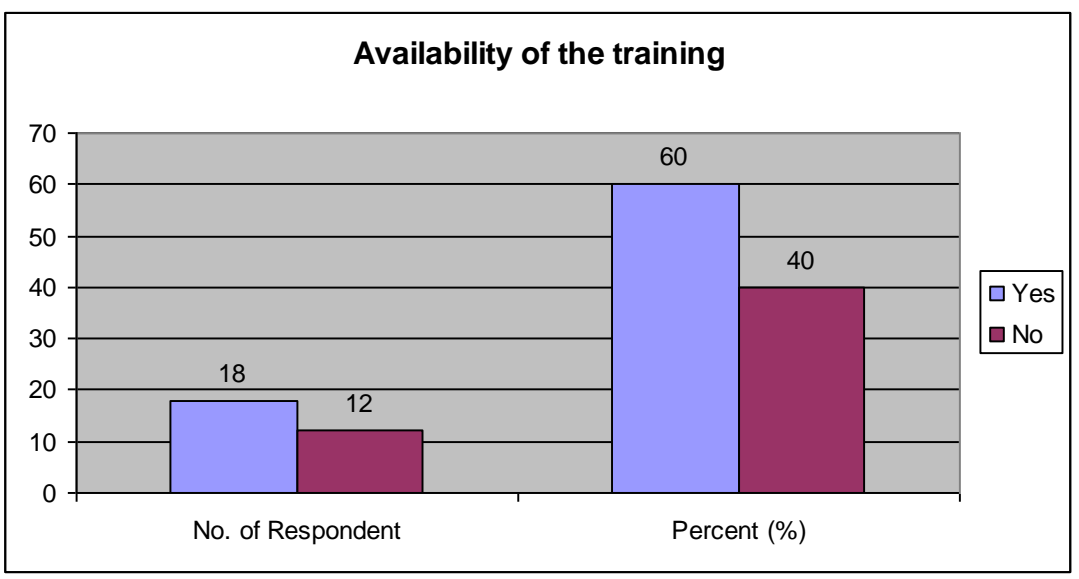

Fig-1; Availability of the training of Nurses

Professional Competencies Improvement through Training

\begin{tabular}{|l|l|l|}
\hline Reply & No. of Respondent & Percent (\%) \\
\hline Yes & 51 & 85 \\
\hline No & 9 & 15 \\
\hline Total & $\mathbf{6 0}$ & $\mathbf{1 0 0 . 0}$ \\
\hline
\end{tabular}


Mukti Rita Gomes., Sch J Med Case Rep, Feb, 2021; 9(2): 150-166

Among the respondents, $85 \%$ replied that the training is important for competencies development through training but $15 \%$ replied that the training have not sure improved their professional performances.

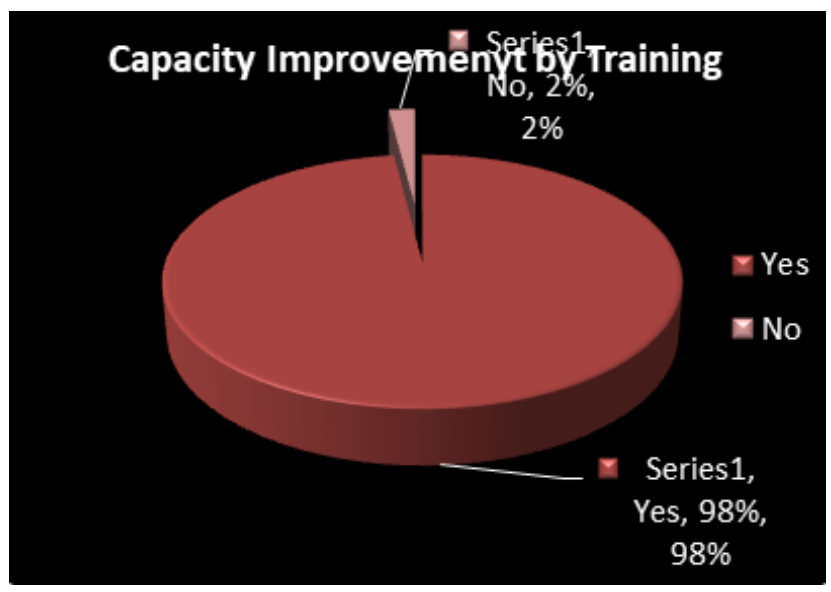

Capacity Improvement by Training

Table. Sufficient Time to Treat and Take Care of the Patients

\begin{tabular}{|l|l|l|}
\hline Reply & No. of Respondent & Percent (\%) \\
\hline Nurse had gotten sufficient time & 39 & 65 \\
\hline Nurse did not get sufficient time & 21 & 35 \\
\hline Total & $\mathbf{6 0}$ & $\mathbf{1 0 0 . 0}$ \\
\hline
\end{tabular}

Among the respondents, $35 \%$ answered that they did not get sufficient time to treat their patient and
$65 \%$ replied that they had sufficient time to treat \& taking care their patient.

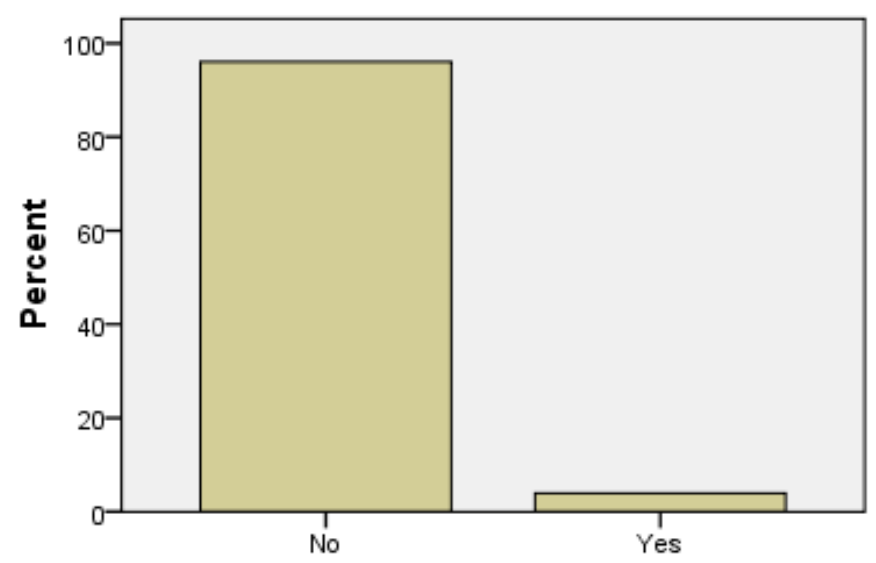

Are you getting sufficient time to treat your patient?

Sufficient Time to Treat Patient

Nurses Reaction about Patient Annoys

\begin{tabular}{|l|l|l|}
\hline Reply & Frequency & Percent (\%) \\
\hline Nothing & 24 & 40 \\
\hline I make a smile \& say it's ok & 27 & 45 \\
\hline I make him/her ashamed & 9 & 15 \\
\hline Total & $\mathbf{6 0}$ & $\mathbf{1 0 0 . 0}$ \\
\hline
\end{tabular}

Table represents that nurse's reaction about patient irritating behaviour. $40 \%$ respondent said that they are received normal behavior, $45 \%$ respondent said that they have accepted those types of annoying behaviors as outcome of illness and accept easily and $15 \%$ respondent replied that they are ashamed about this behaviour. 


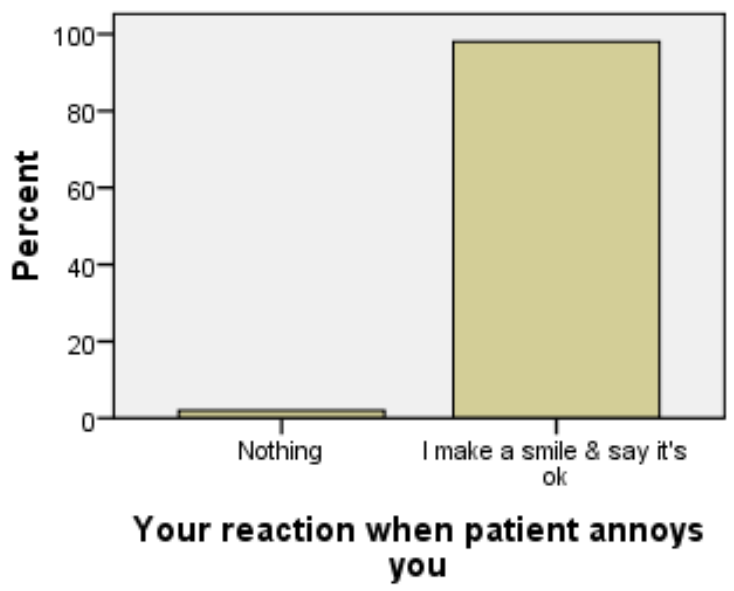

Job Title of the Nurses

\begin{tabular}{|l|l|l|}
\hline Reply & No. of Respondent & Percent (\%) \\
\hline In-charge & 15 & 25 \\
\hline Registered nurse & 36 & 60 \\
\hline Supervisor & 6 & 10 \\
\hline Nursing superintendent & 3 & 5 \\
\hline Total & $\mathbf{6 0}$ & $\mathbf{1 0 0 . 0}$ \\
\hline
\end{tabular}

There are basically four types of job ramification in the respective fields. Among them most of the nurses are entitled in the registered nurse was
$60 \%$, positions like 'In-charge' hold $25 \%$, Supervisor hold $10 \%$ and nursing superintendent was only $5 \%$.

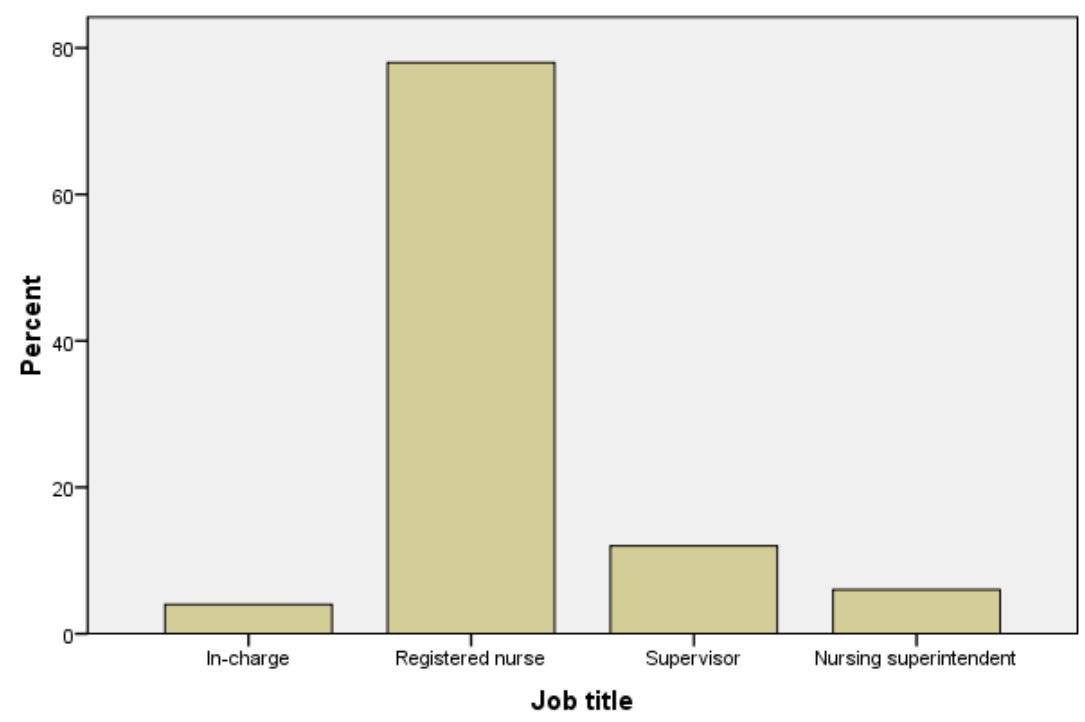

Job Satisfaction of the Nurses

\begin{tabular}{|l|l|l|}
\hline Reply & No. of Respondent & Percent (\%) \\
\hline Noble profession & 27 & 45 \\
\hline Challenging and scope of learning & 15 & 25 \\
\hline Scope of learning & 9 & 15 \\
\hline All of the above & 9 & 15 \\
\hline Total & $\mathbf{6 0}$ & $\mathbf{1 0 0 . 0}$ \\
\hline
\end{tabular}

The respondents were asked to answer the factors that influenced them to be in the nursing jobs. $45 \%$ replied that in this particular job is a noble profession, 25\% answered that they are here in this job because it offers wide range of scopes and challenges of learning, 15\% nurses said that they have scope of learning of nursing sector and $15 \%$ respondents was all of the above about the learning of them. 


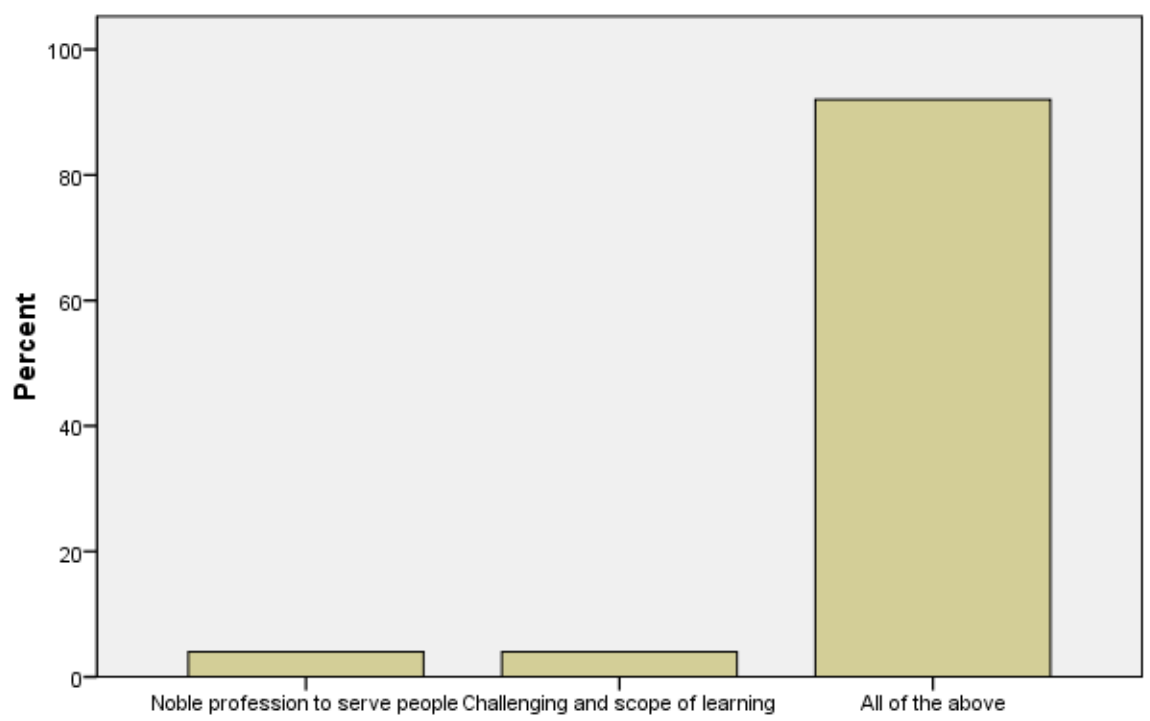

What are the satisfying aspects of your job?

Job Dissatisfaction of the Nurses

\begin{tabular}{|l|l|l|}
\hline Reply & No. of Respondent & Percent (\%) \\
\hline constricted attitude of society and patient & 21 & 35 \\
\hline Lack of remuneration & 24 & 40 \\
\hline This is a typical field & 9 & 15 \\
\hline Other & 6 & 10 \\
\hline Total & $\mathbf{6 0}$ & $\mathbf{1 0 0 . 0}$ \\
\hline
\end{tabular}

The study tends to find out the dissatisfaction aspects of the jobs. Out of the 60 respondents of the study was represented that $35 \%$ respondent i.e., 21 nurses opined that the major problem of job is constricted of society and patient, most of the respondents $40 \%$ i.e. 24 nurses reveals inadequate of remuneration, 9 respondents i.e. $15 \%$ nurses presents that this is a typical job and $10 \%$ respondent i.e. 6 nurses says other causes.

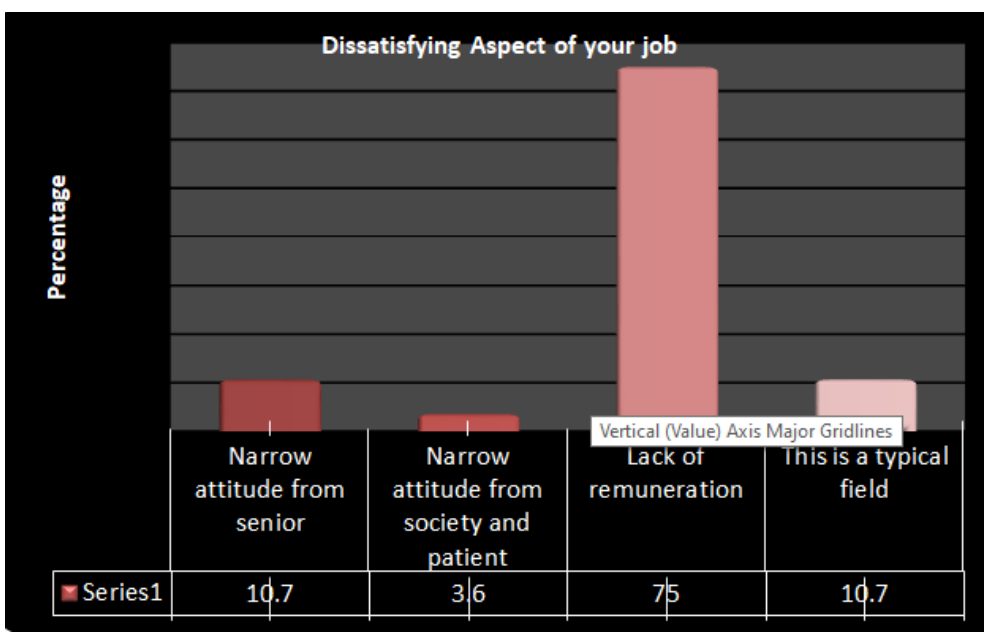

No of promotions received

\begin{tabular}{|l|l|l|}
\hline Promotion Received & No. of Respondent & Percent $(\%)$ \\
\hline 3-5 years promotion & 3 & 5 \\
\hline 6-10 years promotion & 6 & 10 \\
\hline 11-15 years promotion & 6 & 10 \\
\hline Not even one & 45 & 75 \\
\hline Total & $\mathbf{6 0}$ & $\mathbf{1 0 0 . 0}$ \\
\hline
\end{tabular}


The respondents were asked promotions they have received till date. The study shows that $5 \%$ nurse have received their promotion in 3 to 5 years, $10 \%$ nurses have received their promotion in 6 to 10 years,
$10 \%$ nurses have received their promotion in 11 to 15 years and most of the respondents i.e., $75 \%$ nurses have not received any promotion in their service life.

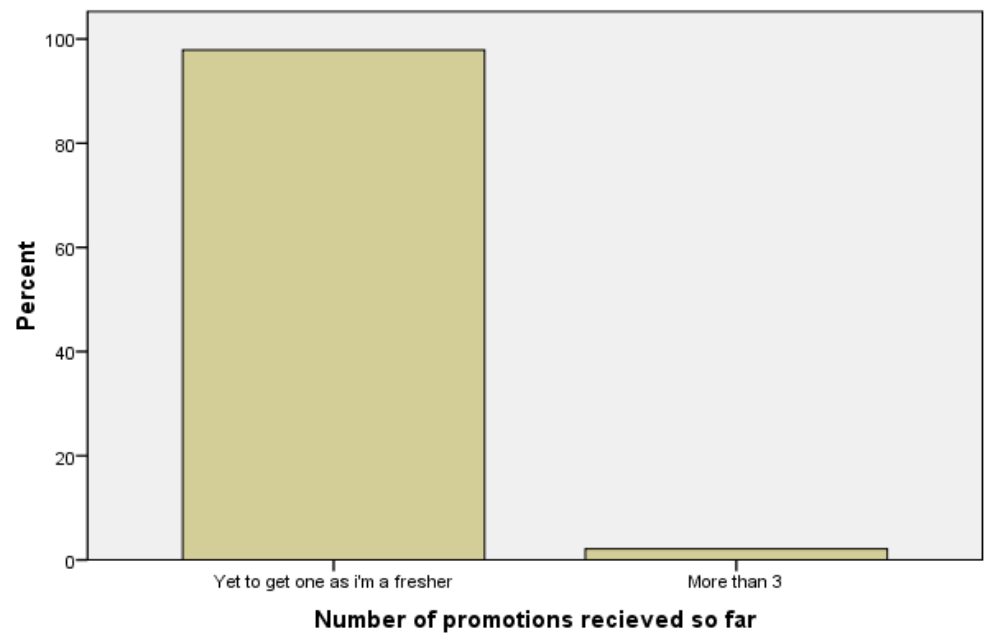

Patients' response

Satisfaction level with admission

\begin{tabular}{|l|l|l|}
\hline Reply & No. of Respondent & Percent (\%) \\
\hline Satisfied & 22 & 55 \\
\hline moderately satisfied & 10 & 25 \\
\hline dissatisfied & 8 & 20 \\
\hline Total & $\mathbf{4 0}$ & $\mathbf{1 0 0 . 0}$ \\
\hline
\end{tabular}

From the survey it was found that $55 \%$ respondent is satisfied with the ongoing admission procedure, $25 \%$ respondent i.e., 10 patients is moderately satisfied and $20 \%$ respondent i.e., 8 patients is dissatisfied with admission in selected hospital.

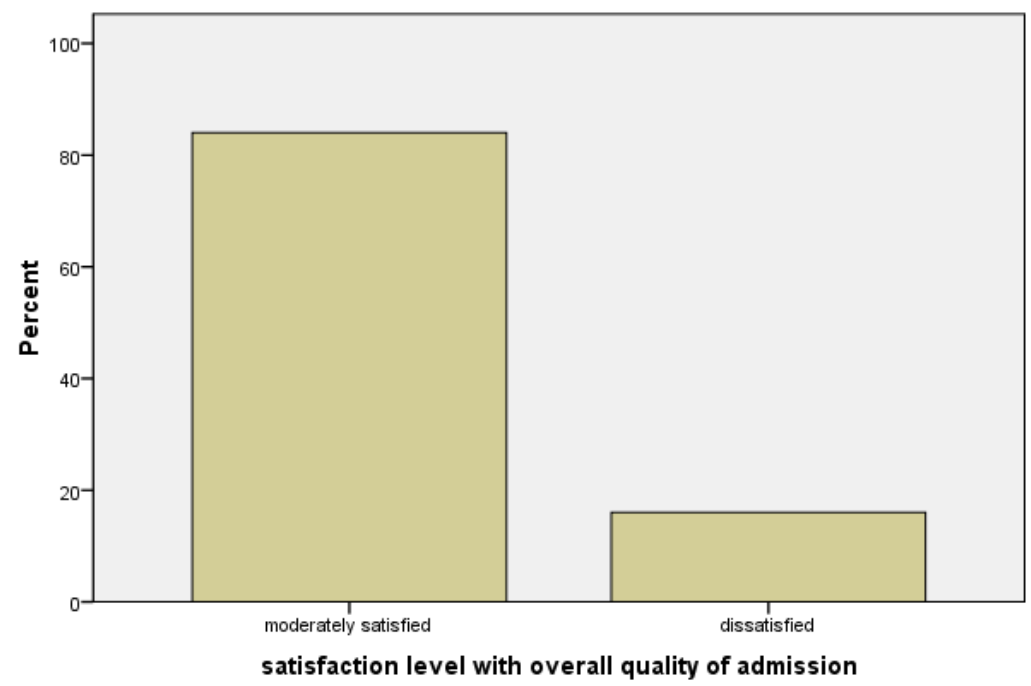

\section{Satisfaction Levels with Treatment \& Care Receive}

\begin{tabular}{|l|l|l|}
\hline Reply & No. of Respondent & Percent (\%) \\
\hline Satisfied & 24 & 60 \\
\hline Dissatisfied & 16 & 40 \\
\hline Total & 40 & 100.0 \\
\hline
\end{tabular}


It was found that most of the patients were satisfied with the treatment \& care received from the nurses. $60 \%$ of the respondents were satisfied and rest of the $40 \%$ was dissatisfied with the level of service from the nurses.

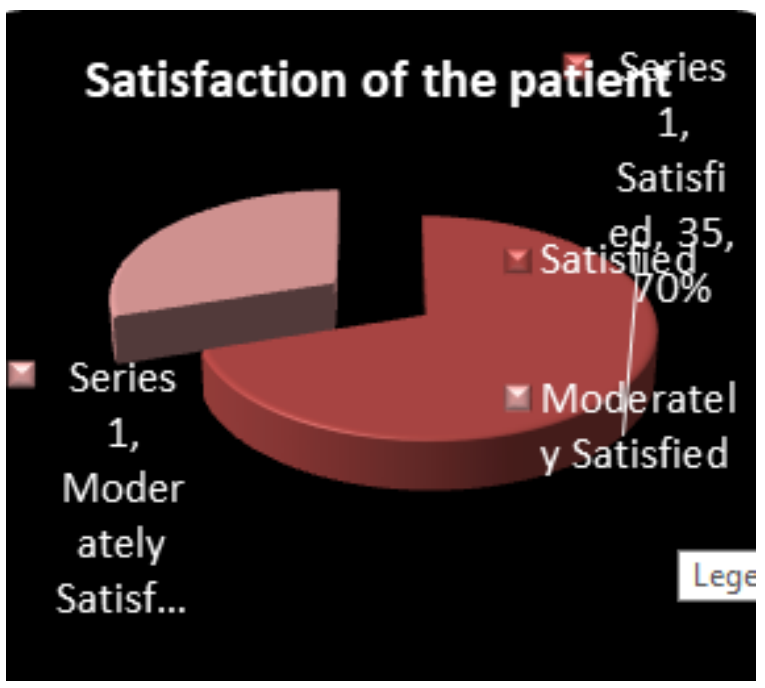

\section{Satisfaction level with the individual care given by} nurses

The patients and their relatives were asked whether they are satisfied with the individual care that is taken by the nurses and in reply all of them said that they are moderately satisfied with the individual care that are taken by the nurses.
The study intends to find out the level of satisfaction with the willingness of the nurses to pay attention to the patient. From the survey it is found that all the respondents are moderately satisfied with this issue. [20]

\begin{tabular}{|l|l|l|}
\hline Reply & No. of Respondent & Percent (\%) \\
\hline very satisfied & 8 & 20 \\
\hline satisfied & 6 & 15 \\
\hline moderately satisfied & 18 & 45 \\
\hline dissatisfied & 8 & 20 \\
\hline Total & 40 & 100.0 \\
\hline
\end{tabular}

This table reveals that satisfaction with the assistance received from nurses. 20\% respondent replied that they are very satisfied, $15 \%$ satisfied, $45 \%$ moderately satisfied \& others $20 \%$ dissatisfied with assistance received from nurses.

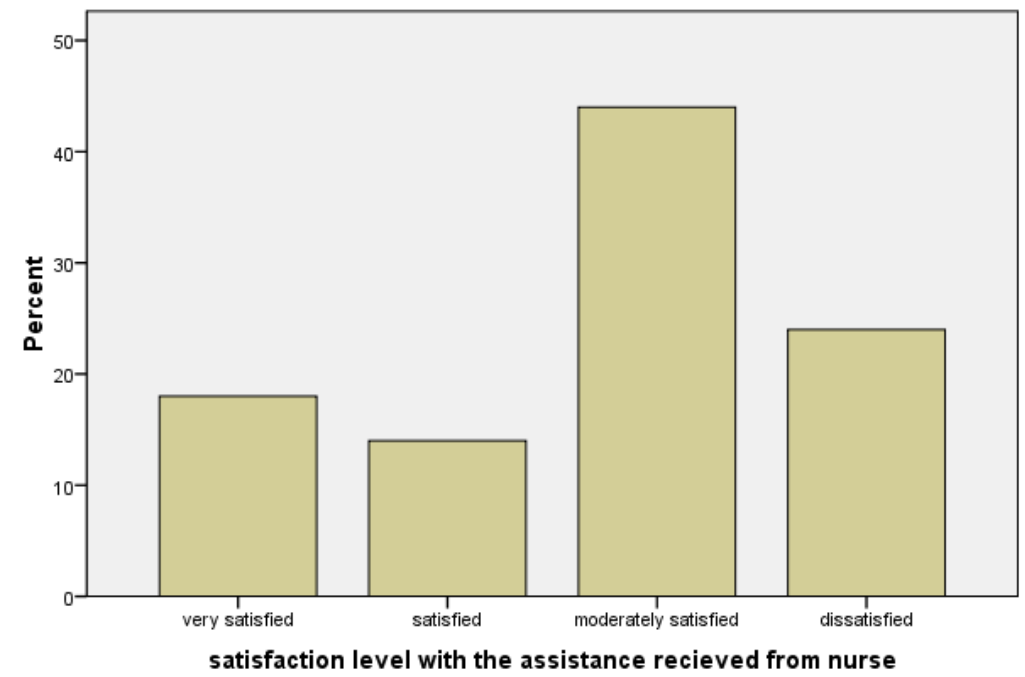




\section{RECOMMENDATION}

Help Hospital Manager and Policy Makers Through-

- Proper planning to develop trained nursing staff of the Oncology.

- Trained personnel may be better utilized through proper placement.

- Non technical work could be replaced by clerical staff or nurse aid.

\section{REFERENCES}

1. Henke C. Emerging roles of the nurse in oncology. In Seminars in oncology 1980 Mar 1 (Vol. 7,No. 1, pp. 4-8).

2. Hilkemeyer R. A historical perspective in cancer nursing. InOncology nursing forum 1985 Jan 1 (Vol. 12, No. 1 Suppl, pp. 6-15).

3. Hubbard SM, Donehower MG. The nurse in a cancer research setting. InSeminars in oncology 1980 Mar (Vol. 7, No. 1, pp. 9-17).

4. Yarbro CH. Duplicate Publication: Guidelines for Nurse Authors and Editors. Journal of post anesthesia nursing. $1996 \mathrm{Feb} ; 11(1): 2-3$.

5. Baird SB. Nursing roles in continuing care: home care and hospice. InSeminars in oncology 1980 Mar 1 (Vol. 7, No. 1, pp. 28-38).

6. Hilderley LJ. The role of the nurse in radiation oncology. InSeminars in oncology 1980 Mar 1 (Vol. 7, No. 1, pp. 39-47).

7. Thaney KM. The nurse in a community hospital setting. InSeminars in oncology 1980 Mar (Vol. 7, No. 1, pp. 18-27).

8. Yarbro $\mathrm{CH}$. Cancer nursing perspectives. The early days: four smiles and a post office box. InOncology nursing forum 1984 (Vol. 11, No. 1, pp. 79-85).

9. Pittsburgh PA. Oncology Nursing Society. Demographics report. Oncology Nursing Society (1999).
10. Washington DC. American Nurses Association: American Nurses Association and the Oncology Nursing Society. Standards of Oncology Nursing Practice (1987).

11. Kansas City. MO.American Nurses Association: Oncology Nursing Society and American Nurses Association Division of Medical Surgical Nursing Practice.Outcome Standards for Cancer Nursing Practice (1989).

12. Washington DC. American Nurses Publishing: American Nurses Association and the Oncology Nursing Statement on the Scope and Standards of Oncology Nursing Practice (1996).

13. Pittsburgh PA.Oncology Nursing Society. Standards of Advanced Practice in Oncology Nursing (1990).

14. McMillan SC, Heusinkveld KB, Spray JA, Murphy CM. Revising the blueprint for the AOCN Examination using a role delineation study for advanced practice oncology nursing. In Oncology nursing forum 1999 Apr 1 (Vol. 26, No. 3, pp. 529537).

15. Pittsburgh PA. Oncology Nursing Certification Corporation. certification bulletin. (1999-2000).

16. Itano JK, Taoko KN. Core curriculumfor oncology nursing.3rd ed. Philadelphia: WB Saunders. (1998).

17. Yarbro $\mathrm{CH}$, Frogge $\mathrm{MH}$, Goodman M, editors. Cancer nursing: principles and practice, 5th ed. Boston, MA: Jones and Bartlett (2000).

18. Yarbro $\mathrm{CH}$, Frogge $\mathrm{MH}$, Goodman M. Cancer symptom management. 2nd ed. Boston, MA: Jones and Bartlett (1999).

19. Gross J, Johnson BL. Handbook of oncology nursing. 2nd ed. Boston, MA: Jones and Bartlett (1994).

20. Dow KH, Hilderley LJ. Nursing care in radiation oncology. Philadelphia, PA: WB Saunders (1992). 